\title{
Traumatic Brain Injury-Induced Hippocampal Neurogenesis Requires Activation of Early Nestin-Expressing Progenitors
}

\author{
Tzong-Shiue Yu (余宗學),, ${ }^{1,2}$ Gui Zhang, ${ }^{1,2}$ Daniel J. Liebl, ${ }^{3}$ and Steven G. Kernie ${ }^{1,2}$ \\ Departments of ${ }^{1}$ Pediatrics and ${ }^{2}$ Developmental Biology, University of Texas Southwestern Medical Center, Dallas, Texas 75390-9133, and ${ }^{3}$ The Miami \\ Project to Cure Paralysis and University of Miami School of Medicine, Miami, Florida 33136
}

It is becoming increasingly clear that brain injuries from a variety of causes stimulate neurogenesis within the hippocampus. It remains unclear, however, how robust this response may be and what primary cell types are involved. Here, using a controlled cortical impact model of traumatic brain injury on a previously characterized transgenic mouse line that expresses enhanced green fluorescent protein (eGFP) under the control of the nestin promoter, we demonstrate that it is the earliest type-1 quiescent progenitor cells that are induced to proliferate and migrate outside the subgranular layer of the dentate gyrus. This type- 1 cell activation occurs at the same time that we observe adjacent but more differentiated doublecortin-expressing progenitors (type-2 cells) being eliminated. Also, although type-2 cells remain intact in the contralateral (uninjured) dentate gyrus, the type-1 cells there are also activated and result in increased numbers of the doublecortin-expressing type- 2 cells. In addition, we have generated a novel mouse transgenic that expresses a modified version of the herpes simplex virus thymidine kinase along with eGFP that allows for the visualization and inducible ablation of early dividing progenitors by exposing them to ganciclovir. Using this transgenic in the context of traumatic brain injury, we demonstrate that these early progenitors are required for injury-induced remodeling to occur. This work suggests that injury-induced hippocampal remodeling following brain injury likely requires sustained activation of quiescent early progenitors.

Key words: traumatic brain injury; hippocampus; dentate gyrus; neurogenesis; neuroprotection; neuronal progenitor cell

\section{Introduction}

Traumatic brain injury (TBI) is the most common form of acquired brain injury in both children and adults in the United States (Marshall, 2000; Chirumamilla et al., 2002). Furthermore, TBI causes neuronal loss and results in a variety of neurological and cognitive deficits, especially in hippocampus-dependent functionality (Bramlett et al., 1997; Levin, 1998). However, several studies in animal models that mimic TBI demonstrate that there is also enhanced generation of newly born neurons in the dentate gyrus, an area of the brain where ongoing neurogenesis is known to occur throughout life in all mammals including humans (Kernie et al., 2001; Rola et al., 2006; Richardson et al., 2007; Urrea et al., 2007). It remains unclear what relevance injury-induced neurogenesis may have in the recovery process following TBI.

Neural progenitors in the mature dentate gyrus reside primarily in the subgranular layers. These cells are subdivided into type 1 (putative neural stem cells), type 2a (early neural progenitors), type $2 \mathrm{~b}$ (committed neuronal progenitors), and type 3 cells based on specific markers and electrophysiologic characteristics

Received Sept. 24, 2008; accepted 0ct. 17, 2008.

This work was supported by National Institutes of Health Grants R01 NS048192 (S.G.K.) and R01NS049545 (D.J.L., S.G.K.). We thank Ben Orr for his technical assistance and Josh Koch for help with statistical analysis.

This article is freely available online through the J Neurosci Open Choice option.

Correspondence should be addressed to Steven G. Kernie, Department of Developmental Biology, University of Texas Southwestern Medical Center, 5323 Harry Hines Boulevard, Dallas, Texas 75390-9133. E-mail: Steven.Kernie@utsouthwestern.edu.

D0I:10.1523/JNEUROSCI.4629-08.2008

Copyright $\odot 2008$ Society for Neuroscience $\quad$ 0270-6474/08/2812901-12\$15.00/0
(Fukuda et al., 2003; Kronenberg et al., 2003). To distinguish between these various subtypes of progenitors, mouse transgenic lines have been constructed that express GFP under the control of the neural progenitor-specific form of the nestin promoter and its second intron regulatory element (Yamaguchi et al., 2000; Mignone et al., 2004; Yu et al., 2005). We took advantage of one such line to identify and monitor neural progenitors based on the expression of GFP and we characterized the dynamics of neural progenitor activation in the traumatically injured brain. In addition to describing injury-induced progenitor activation, we also sought to determine whether early type 1 progenitors are required for this activation to occur. To do this, we generated another transgenic mouse line that contains a modified version of the herpes simplex virus thymidine kinase ( $\delta$-HSV-TK) driven by the nestin promoter and its second intron regulatory element. This allows for temporally regulated ablation of dividing neural progenitors by systemic administration of ganciclovir.

Here, we used these two transgenic lines and performed unilateral controlled cortical impact (CCI) injury on them to demonstrate that doublecortin (DCX)-expressing late neural progenitors are relatively vulnerable to brain injuries whereas adjacent enhanced green fluorescent protein (eGFP)-expressing early neural progenitors are activated. The activated early neural progenitors repopulate lost DCX-expressing late progenitors not only in the subgranular layers of the dentate gyrus, but also in the granular layers as well. Moreover, we find that by selective ablation of dividing type 1 and 2a progenitors, replacement of DCXexpressing late progenitors is completely inhibited. In addition, 
when uninjured mice are pretreated with ganciclovir, only slowly dividing type 1 cells remain and following injury, these type 1 cells are activated and function to repopulate lost late progenitors. These data suggest that a subset of neural progenitors reside in the granular layer and are quiescent in the normal brain but became active after injury and can compensate for the injury-induced loss of granular neurons.

\section{Materials and Methods}

Animals. Experimental animals were housed and cared for in the Animal Resource Center (ARC) at University of Texas Southwestern Medical Center (UTSWMC), which is certified by the Association for Assessment and Accreditation of Laboratory Animal Care. All animal experiments were conducted with previous approval of the Institutional Animal Use and Care Committee at UTSWMC in compliance with the highest standard for the humane and compassionate use of animals in biomedical research.

Generation of modified herpes simple virus ( $\delta$ $H S V-T K)$ transgenic mice. We obtained a construct containing HSV-TK (from J. Graff, UTSW) and designed primers to amplify an $\sim 1.1 \mathrm{~Kb} \delta$-HSV-TK fragments with EcoRI and BamHI sites on the $5^{\prime}$ and $3^{\prime}$ end, respectively. The sequences of the primers were as follows: forward primer: $5^{\prime}-\mathrm{ccg}$ aat tca agc tta tgc cca cgc tac tgc gg- $3^{\prime}$, and reverse primer: $5^{\prime}$-cgg gat $\mathrm{ccc}$ gtc agt tag cct ccc cca tct c- $3^{\prime}$. The PCR conditions were one cycle of $94^{\circ} \mathrm{C}, 1 \mathrm{~min}$, followed by 35 cycles of $94^{\circ} \mathrm{C}$ for $1 \mathrm{~min}, 60^{\circ} \mathrm{C}$ for $2 \mathrm{~min}, 72^{\circ} \mathrm{C}$ for $3 \mathrm{~min}$. The final extension was one cycle of $72^{\circ} \mathrm{C}$ for $10 \mathrm{~min}$. The amplified fragment was used to replace the rtTA-M2 fragment on pNERV/rtTA-M2/IRES-eGFP construct with EcoRI (New England Labs) and BamHI (New England Labs) sites (Yu et al., 2005). The linearized plasmid was cut with SalI to remove the pUC fragment and purified with EluTip D (Whatman). Transgenic mice were generated by pronuclear injection into fertilized murine eggs in a C57BL/6 genetic background. To verify whether the transgene was transmitted, genomic DNA was extracted from tails at P21 to perform PCR to amplify the eGFP fragment. The primers used to verify eGFP were: forward primer, $5^{\prime}$-gag ctg gac ggc gac gta aac-3' and the reverse primer, $5^{\prime}$-cgt tgt ggc tgt tgt tag ttg tac- $3^{\prime}$. The PCR conditions were one cycle of $94^{\circ} \mathrm{C}$ for $2 \mathrm{~min}$, followed by 35 cycles of $94^{\circ} \mathrm{C}, 1 \mathrm{~min}$, $59^{\circ} \mathrm{C}, 1 \mathrm{~min}$, and $72^{\circ} \mathrm{C}$ for $2 \mathrm{~min}$, and one cycle of $72^{\circ} \mathrm{C}$ for $10 \mathrm{~min}$.

Total RNA extraction and reverse transcribed PCR. Total RNA was extracted from tissues and reverse transcribed (Invitrogen). PCR primers were as follows: $\delta$-HSV-TK (forward: $5^{\prime}$-gcc ttg acc agg gtg aga ta- $3^{\prime}$; reverse: $5^{\prime}$-atg ctg ccc ata agg tat cg- $3^{\prime}$ ) and GAPDH (forward: $5^{\prime}$-acc aca gtc cat gcc atc ac- $3^{\prime}$; reverse: $5^{\prime}$-tcc acc acc ctg ttg ctg ta- $\left.3^{\prime}\right)$. Primers were used at $100 \mu \mathrm{g} /$ reaction. PCR amplification of cDNA was performed in PCR buffer containing $0.5 \mathrm{~mm}$ dNTPs and $0.5 \mathrm{U}$ Taq polymerase (Invitrogen) on a thermal cycler (Thermo Electron). PCR products were separated on an agarose gel and stained with ethidium bromide.

CCI injury. To perform CCI, the standard protocol and a controlled cortical impact device used to generate brain injuries were used as previously described (Kernie et al., 2001). Eight-week-old male wild-type or transgenic mice were anesthetized with $0.15 \mathrm{ml}$ of ketamine $(100 \mathrm{mg} / \mathrm{ml})$ : xyzaline $(20 \mathrm{mg} / \mathrm{ml})$ 10:1 mixture. Mice were placed in a stereotactic frame. A midline incision was made, the soft tissues were reflected, and a $5 \mathrm{~mm}$ by $5 \mathrm{~mm}$ craniectomy was made between bregma and $\lambda$ and $1 \mathrm{~mm}$ lateral to the midline. The injury was generated with a $3 \mathrm{~mm}$ stainless steel tipped impact device with a deformation of $0.7 \mathrm{~mm}$ and constant speed of $4.4 \mathrm{~m} / \mathrm{s}$. After injury, the scalp was fastened with staples and the mice were allowed to recover. Following injury, BrdU $(100 \mathrm{mg} / \mathrm{Kg}$, Sigma) was injected intraperitoneally at 12 and $2 \mathrm{~h}$ before killing. A total of 4-5 animals were injured for each experimental group tested unless otherwise indicated. A total of 40 8-week-old animals (25-35 g) were used for injury experiments and 24 animals were used for noninjury experiments.

Immunohistochemistry. All mice were deeply anesthetized with ketamine and xylazine mixture as described above before perfusion. The transcardiac perfusion was performed with $50 \mathrm{ml}$ of $1 \times \mathrm{PBS}$, followed by $50 \mathrm{ml}$ of $4 \%$ paraformaldehyde (PFA) in PBS. Following postfixation in $4 \% \mathrm{PFA} / 1 \times \mathrm{PBS}$ overnight, whole brains were dissected and embedded in $3 \%$ agarose $/ 1 \times$ PBS. Serial $50 \mu \mathrm{m}$ sections were cut with a vibratome (VT1000S, Leica). All sections encompassing the hippocampus were collected sequentially in 12-well plates. Free-floating sections were used for immunohistochemistry. For BrdU staining, all sections from a single well were washed with $1 \times \mathrm{PBS} 3$ times and rinsed with water. Then, sections were denatured with $0.1 \mathrm{~N} \mathrm{HCl}$ for $1 \mathrm{~h}$ in $37^{\circ} \mathrm{C}$ water bath. After denaturation, sections were neutralized with $0.1 \mathrm{M}$ Borax, $\mathrm{pH} 8.5$ (Sigma) for 10 min. Sections were washed with $0.3 \%$ Triton X-100/1×PBS (wash buffer) for 3 times and blocked with 5\% normal donkey serum (SigmaAldrich) contained wash buffer for $1 \mathrm{~h}$ at room temperature. 1:200 ratanti BrdU (Abcam) antibody was used to label BrdU overnight at $4^{\circ} \mathrm{C}$. The following day, sections were incubated with Cy5-conjugated anti-rat antibody (all 1:200, Jackson Immunoresearch) for $3 \mathrm{~h}$ at room temperature. The sections were placed on the slides and covered with coverslips for confocal microscope observation after antibody incubation. For regular staining the protocol was as above for the BrdU except sections were 


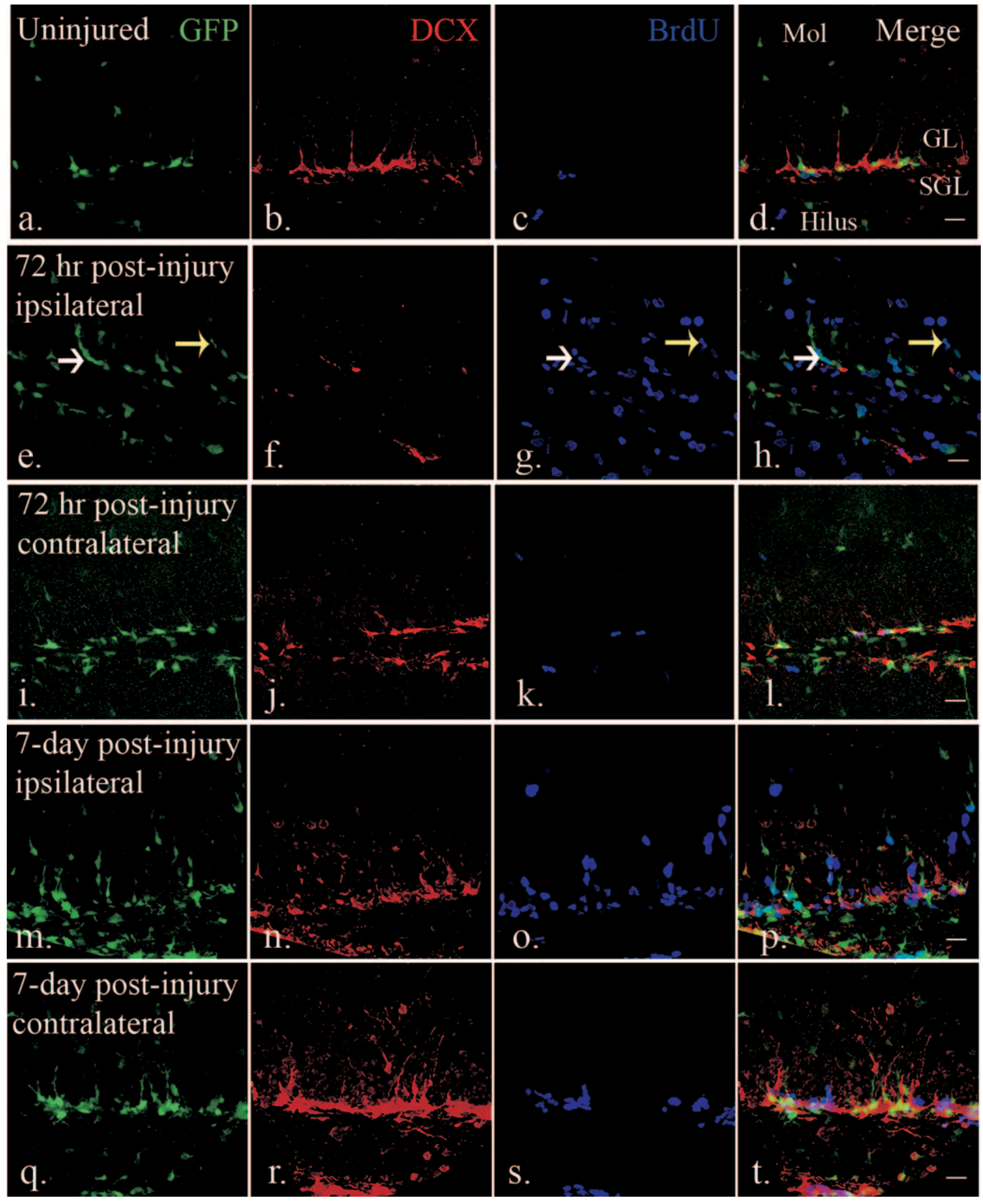

Figure 2. The distribution and response of neural progenitors in the adult dentate gyrus after $\mathrm{CCl}$ injury. $\boldsymbol{a}-\boldsymbol{d}$, eGFP- and DCX-expressing cells were found in the subgranular and granular layers of the dentate gyrus. BrdU-labeled cells were rarely seen in the dentate gyrus in uninjured mice. ( $\boldsymbol{e}-\boldsymbol{h}$, After injury $(72 \mathrm{~h})$, eGFP-expressing early neural progenitors were detected in the subgranular layers (white arrow), as well as granular layers (yellow arrow). There is an apparent decrease of $D C X$-expressing late neural progenitors in the dentate gyrus in the ipsilateral hemispheres $(\boldsymbol{f})$ at the same time that abundant BrdU-labeled cells were found in the dentate gyrus $(\boldsymbol{g})$. $(\boldsymbol{i}-\boldsymbol{I})$ In the contralateral dentate gyrus, there is minimal apparent activation of GFP-expressing cells that mimics the control dentate gyrus. $\boldsymbol{m}-\boldsymbol{p}$, Robust numbers of eGFP-expressing cells persist in the ipsilateral dentate gyrus $7 \mathrm{~d}$ after injury $(\boldsymbol{m})$. DCX-expressing late neural progenitors are more recovered at this time point $(\boldsymbol{n})$ and there remains a large number of BrdU-positive cells $(\boldsymbol{o})$. $\boldsymbol{q}-\boldsymbol{t}$, There is also an apparent increase in cell number and proliferation of both eGFP $(\boldsymbol{q})$ and DCX-expressing $(\boldsymbol{r})$ cells in the contralateral dentate gyrus $7 \mathrm{~d}$ after injury. Scale bars, $20 \mu \mathrm{m}$. Mol, Molecular layer; SGL, subgranular layer; GL, granular layer. 
not treated with $\mathrm{HCl}$ and Borax. Primary antibodies used in this study were as follows: rabbit anti-GFP (1:500, Molecular Biology), chicken anti-GFP (1:200, AbCam), mouse anti-GFAP (1:100, BD PharMingen), rabbit anti-GFAP (1:500, DAKO), goat anti-doublecortin (1:100, Santa Cruz biotech), mouse anti-vimentin (1:200, 40E-C, Hybridoma Bank, University of Iowa), rabbit anti-Ki67 (1:200, NeoMarkers), mouse antiNeuN (1:500, Chemicon), rabbit anti-NG2 (1:200, Chemicon), rat antiPDGFRa (1:200, BD PharMingen), and goat anti-Iba-1 (1:200, AbCam), rabbit anti-TK serum (1:10, from Dr. William Summers, Yale University). For secondary antibodies, Cy2-, Cy3- or Cy5-conjugated donkey anti-species antibodies were used (all 1:200, Jackson ImmunoResearch).

Fluoro-Jade C staining. To determine whether the decrease in DCXpositive cell number was due to neuronal degeneration and likely cell death, Fluoro-Jade C (Millipore) staining was used. Because the signal is visualized by using a Cy2/FITC filter, wild-type mice were used to avoid any interference from eGFP signals in transgenic mice. Mice were killed and perfused with $4 \% \mathrm{PFA} / 1 \times \mathrm{PBS}$ at 24 and $48 \mathrm{~h}$ after $\mathrm{CCI}$ injury $(N=$ 4 each time points). Vibratome sections ( $50 \mu \mathrm{m})$ encompassing the hippocampus were collected and mounted on slides. Sections were first immunostained by using goat anti-doublecortin antibody (1:100, N-19, Santa Cruz biotech) and donkey anti-goat IgG (1:200, Jackson ImmunoResearch) and then mounted on slides (described as above). The sections were allowed to dry at room temperature for $20 \mathrm{~min}$ in the dark. Sections were washed with water for $5 \mathrm{~min}$, then transferred directly to the freshly prepared $0.06 \%$ potassium permanganate solution for $5 \mathrm{~min}$, stained with $0.0004 \%$ Fluoro-Jade C for $15 \mathrm{~min}$, washed twice with water for $5 \mathrm{~min}$ and coverslipped for confocal microscopy.

Quantification and confocal microscopy. For cell quantification we used a traditional and well established method to account for oversampling as described in detail previously (Guillery, 2002; Miles and Kernie, 2008). A Zeiss LSM 510 confocal microscopy using Argon 488, He 543 and He 633 lasers and a Zeiss Neofluar $40 \times / 1.3$ oil lens was used to determine colocalization of immunohistochemical markers and cell quantification with a pinhole aperture of 3.46 Airy units. Cell quantification was performed from the ipsilateral, contralateral dentate gyrus and dentate gyrus from uninjured mice and injured mice. All brains were embedded in 3\% agarose and cut with a vibrating microtome (Leica) at $50 \mu \mathrm{m}$ thickness using a sapphire blade in $0.1 \mathrm{~m}$ PBS. Free-floating sections through the entire rostral to caudal hippocampal axis were collected in 12-well plates with 5 sections/well. We sampled one well of five sections $50 \mu \mathrm{m}$ thick, coronally cut, and paraformaldehyde-fixed $600 \mu \mathrm{m}$ apart. Five sections from each well were stained with specific markers as free-floating sections to allow for equal antibody penetration between sections. Sections were mounted using Immunomount with a refractive index of 1.495. Antibody penetration and signal intensity were found to be evenly distributed throughout the $z$-axis in multiple sections from different animals. Each blade of the dentate gyrus was counted separately at $40 \times$ under Zeiss immersion oil $518 \mathrm{~F}$ with $1.5 \times$ optical zoom magnification. Nonblinded quantification was performed on cells with fully colocalized relevant cell markers. By scanning serially through the $z$-axis of each cell, a more precise discrimination of the colocalization of relevant cell markers was permissible. Since $1 / 12$ of the total number of sections was counted, we multiplied our counts by 12 to obtain the number of cells per dentate gyrus. When compared with counts done with unbiased stereology (see below), the totals using this method are very similar as total counts given are per dentate gyrus and the data presented using stereology provide counts per hippocampus.

To determine the number of GFP- and DCX-expressing cells in the dentate gyrus after ganciclovir treatment, we used an unbiased stereological approach. A one-in-six series of sections covering the entire hippocampus in its rostrocaudal extension were immunostained and visualized under light microscopy with the peroxidase/diaminobenzidine (DAB) method. The cells were counted using a modified optical fractionator and stereological image analysis software (StereoInvestigator, Microbrightfield) operating a computer-driven Olympus microscope regulated in the $x, y$, and $z$ axes. Areas to be counted were traced with a $20 \times$ objective lens and sample frames $(80 \mu \mathrm{m} \times 80 \mu \mathrm{m})$ were selected at random by the image analysis software. Cells in the counting frame (40 $\mu \mathrm{m} \times 40 \mu \mathrm{m})$ were counted under a $40 \times$ objective lens. To avoid over- sampling, the uppermost and lowermost focal planes were excluded. The total cell number of cells was estimated by multiplying the resulting counts by 6 , since every sixth section had been used. Hence, the numbers obtained in this study are absolute numbers per hippocampus (both sides of the dentate gyrus counted for each) and are independent of the volume of the dentate gyrus.

Ganciclovir administration. Ganciclovir $(200 \mathrm{mg} / \mathrm{Kg} / \mathrm{d}$, Cytovene-IV, Roche Pharmaceuticals) or vehicle $\left(\mathrm{dH}_{2} \mathrm{O}\right)$ was delivered via osmotic mini pumps that infuse at a constant rate of $0.5 \mu$ l per hour for 2 weeks (model 2002, Alzet). The pumps were replaced every 2 weeks based on the requirement of each experiment. The implantation of pumps was as per the Alzet protocol and is briefly described below: 6-week-old mice were anesthetized with isoflurane. A small incision was made in the skin between the scapulae and a small pocket was formed by using a hemostat to spread the subcutaneous connective tissue apart. The pumps were inserted into the pocket with the opening of pumps pointing away from the incision. The skin incision was closed with staples.

Statistics. Statistics were done using a one-way ANOVA for multiple comparisons with a Newman-Keuls multiple comparison test for post hoc analysis. A Student's $t$ test was performed for paired data. Differences were deemed significant with $p<0.05$.

\section{Results \\ Nestin-eGFP transgenic mice specifically label early hippocampal stem/progenitor cells}

Previous studies have shown that TBI induces neurogenesis primarily in the dentate gyrus (Kernie et al., 2001; Chirumamilla et al., 2002; Rola et al., 2006; Richardson et al., 2007; Sun et al., 2007; Urrea et al., 2007). To describe in detail the dynamics of adult hippocampal neural progenitors in the traumatically injured brain and explore the mechanisms involved, we generated transgenic mice that express eGFP under the control of the nestin promoter and used them to perform unilateral CCI injury as a model of acquired TBI (Yu et al., 2005).

One of the most commonly used criteria for neural stem and progenitor cells is expression of the intermediate filament nestin. Nestin, however, is expressed in other non-neural progenitor cell types including developing muscle, endothelial cells, and reactive astrocytes (Zimmerman et al., 1994; Ridet et al., 1997). Therefore, we generated a transgenic mouse that uses the neural progenitor-specific form of the nestin promoter to direct expression of eGFP specifically in neural stem and progenitor cells (Yu et al., 2005). Thus, by using the fact that eGFP expression is exclusive to early neural progenitors and by using other well characterized immunohistochemical markers, we were able to easily distinguish early type 1 , type 2 , and late type 3 progenitors within the dentate gyrus. We identified a slowly dividing type 1 cell as one that expresses nestin-eGFP, incorporates BrdU, and contains a Vimentin or GFAP-expressing process that colocalize together and originate from the same cell (Fig. $1 a, b, d$ ). We define a proliferating type 2 a cell as one that expresses eGFP but lacks a radial process (Fig. 1d). As a type 2 a cell differentiates, nestin-eGFP expression is downregulated and the immature neuronal marker DCX begins to be expressed. A type $2 \mathrm{~b}$ cell represents this transition between early and late progenitors and no longer expresses eGFP but does express DCX (Fig. 1c). Expression of eGFP in sham and activated type 1 GFAP-expressing cells overlaps completely with nestin protein expression detected by immunohistochemistry in vivo, supporting the validity of nestin-eGFP expression as a marker for neural stem cells (Shi et al., 2007; Miles and Kernie, 2008). 
a. Ipsilateral

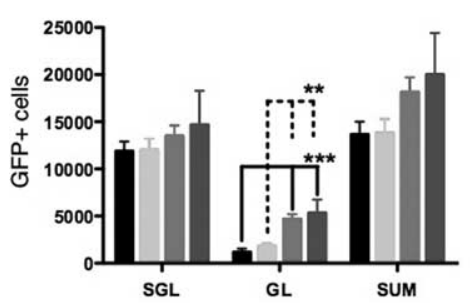

C.

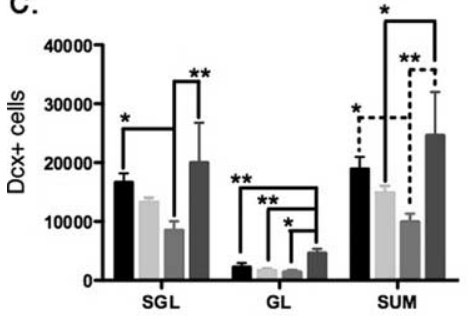

b. Contralateral

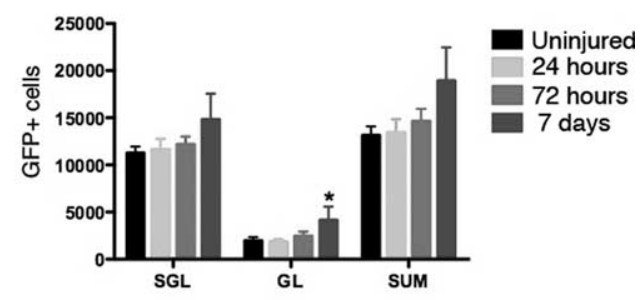

d.

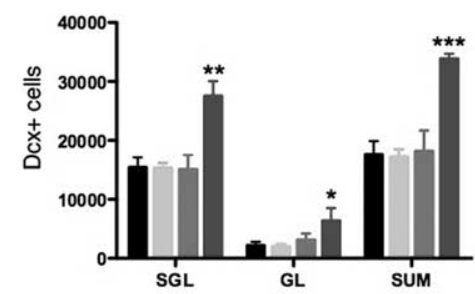

Figure 3. Quantification of early and late neural progenitors in the dentate gyrus after injury. In the uninjured brains, there were similar numbers of eGFP-expressing cells in the dentate gyrus in both hemispheres (16,647 \pm 3046 and 15,417 \pm 3407 in the subgranular layers, $2259 \pm 1370$ and $2169 \pm 1266$ in the granular layers; mean \pm SD). $\boldsymbol{a}$, In the ipsilateral dentate gyrus, no significant change was observed in the early neural progenitors in the subgranular layers (SGL). A significant increase in the number of early neural progenitors was observed in the granular layers $(\mathrm{GL})(p=0.0001$, one-way ANOVA). Post hoc analysis revealed a significant increase of early neural progenitors $72 \mathrm{~h}$ and $7 \mathrm{~d}$ after $\mathrm{CCl}$ injury $(p<0.01)$ when compared with uninjured samples and $24 \mathrm{~h}$ after injury and the increase in the granular layers contributed to a significant increase in total neural progenitor number ( $p=0.0474$, one-way ANOVA). $\boldsymbol{b}$, A similar phenomenon was noted in the contralateral dentate gyrus, with no significant change in the subgranular layers but increases in the granular layers ( $p=0.1221,0.0229$, and 0.0433 in subgranular layers, granular layers and total (SUM), respectively, one-way ANOVA). c, The opposite result was seen in the DCX-expressing late neural progenitor population where in the ipsilateral dentate gyrus, there was a significant difference in both layers examined ( $p$ $=0.0116,0.0016$ and 0.0050 for DCX-expressing cell number in subgranular layers, granular layers and total). In the subgranular layer, there was a significant decrease in late neural progenitors $72 \mathrm{~h}$ after the injury compared with $7 \mathrm{~d}$ after the injury, when the cell population had returned to baseline ( $p<0.05$ with post hoc Newman-Keuls multiple comparison test). The granular layer revealed a similar increase $7 \mathrm{~d}$ after the injury when compared with uninjured group, 24 and $72 \mathrm{~h}$ after injury $(p<0.01)$. $d$, In the contralateral dentate gyrus, the DCX-expressing cell number remained unchanged $72 \mathrm{~h}$ after injury, but increased significantly $7 \mathrm{~d}$ after injury in both the subgranular and granular layers $\left({ }^{*} p<0.05,{ }^{* *} p<0.01,{ }^{* * *} p<0.0001\right.$ with post hoc Newman-Keuls multiple comparison test). $N=4$ in each group; error bars indicate SEM.

\section{eGFP-expressing cells are distinguishable from other cell types following injury}

Nestin, itself is expressed in several cell types, such as NG2expressing oligodendrocyte progenitor cells, reactive astrocytes, and endothelial cells, especially in the injured brain (Ridet et al., 1997; Belachew et al., 2003; Aguirre and Gallo, 2004; Yokoyama et al., 2006). Although the promoter and regulatory elements of the nestin gene we used are specific to neural progenitors, it is not known whether those fragments were involved in nestin expression in other cell types. To clarify whether eGFP was expressed in other cells after injury, a moderately severe CCI injury was performed on 8-week-old male transgenic animals. We define this moderately severe injury as one that essentially ablates the overlying cortex by mechanical damage and, while leaving the underlying hippocampus structurally intact, causes diverse secondary damage to a variety of cell types within the dentate gyrus (supplemental Fig. 1 $a$, available at www.jneurosci.org as supplemental material). In mice killed $3 \mathrm{~d}$ after injury, eGFP-expressing cells in the dentate gyrus were distinguishable from reactive astrocytes, which were defined as cells with increased expression of GFAP and hypertrophy (supplemental Fig. 1b, available at www. jneurosci.org as supplemental material). Likewise, we demonstrate that eGFP-expressing cells do not express markers for immature glia such as NG-2 and $\operatorname{PDGFR} \alpha$, nor do they express the microglia-specific marker Iba-1 (supplemental Fig. $1 c-e$, avail- able at www.jneurosci.org as supplemental material). Therefore, we conclude that eGFP-expressing cells in the dentate gyrus were distinguishable from NG2-expressing oligodendrocyte precursor cells, reactive astrocytes, and active microglia and thus represent early neural progenitors.

\section{Early and late neural progenitors demonstrate opposing responses following unilateral CCI injury}

To describe the dynamics of adult neural progenitors in the dentate gyrus after CCI injury, we used 8-week-old male eGFPexpressing transgenic animals and performed unilateral CCI injury and killed them 1,3 , and $7 \mathrm{~d}$ after injury and compared them to uninjured littermates. Twelve and $2 \mathrm{~h}$ before sacrifice, a BrdU dose $(100 \mathrm{mg} / \mathrm{Kg})$ was given to label the dividing cells. As detailed above, the obviously injured site was restricted to the cortex overlying the hippocampus while we observe evidence of referred damage to the grossly intact hippocampus.

Following injury, the two adjacent progenitor populations behave with distinct differences. At $72 \mathrm{~h}$ following injury, the injured side has increased numbers of eGFP-expressing progenitors whereas the DCX-expressing late progenitors are significantly decreased, and this occurs in a highly proliferative environment as evidenced by BrdU pulsing (Fig. $2 e-h$ ). At $7 \mathrm{~d}$ postinjury, eGFP-expressing cells increase further on the ipsilateral side and the DCX-expressing population reestablishes itself while the proliferative environment is maintained (Fig. $2 m-p$ ). Interestingly, the contralateral side also demonstrates activation of eGFP-expressing progenitors, but unlike the injured side, has enhanced numbers of DCXexpressing late progenitors as early as $7 \mathrm{~d}$ following injury (Fig. $2 q-t)$.

To determine the amount and location of eGFP- and DCXexpressing progenitors following injury, we quantified their distribution within the dentate gyrus. We designated the innermost 2 cell layers as the subgranular layer and the remaining neuronal layers the granular layer. These anatomic distinctions are a minor modification of what has been described previously (Kempermann et al., 2003; Mandyam et al., 2004) and allowed us to distinguish between truly resident type-1 quiescent subgranular progenitors with those that appeared to be activated and more migratory. In the subgranular layer, there is no change in the number of eGFP-expressing cells at 1,3 , or $7 \mathrm{~d}$ following injury (Fig. 3a). In the granular layer, however, there is a clear increase that occurred $3 \mathrm{~d}$ after injury and persisted for at least $7 \mathrm{~d}$ (Fig. $3 a$ ). Doublecortin-expressing cells decrease at $72 \mathrm{~h}$ but then rebound by $7 \mathrm{~d}$ within the subgranular layer and actually increase above baseline in the granular layer (Fig. $3 c$ ). Diminished doublecortin expression may occur as a change in differentiation although when coupled with Fluoro Jade C staining to mark neuronal degeneration, the degenerating cells are largely confined to the DCX-expressing cells in the subgranular and granular zones 
(supplemental Fig. 2a-c, available at www. jneurosci.org as supplemental material). On the contralateral side, where cell death in the hippocampus is not observed, the increase in eGFP and doublecortin expression is even more dramatic, whereby there is an increase of both eGFP-expressing cells in the granular layer at $7 \mathrm{~d}$ and DCXexpressing cells in both the subgranular and granular layers (Fig. 3b,d).

Next, we used BrdU incorporation as a marker to determine what cells were proliferating at the time of sacrifice $(1,3$, and $7 \mathrm{~d}$ post injury). Since BrdU incorporation in the setting of injury can at least in theory occur during DNA repair, we first examined whether BrdU-positive cells also coexpressed a marker of cell division, Ki67. We determined that, in fact, all cells that express BrdU also express Ki67, although also as expected, not all Ki67-expressing cells express BrdU (supplemental Fig. $2 g-i$, available at www.jneurosci.org as supplemental material). In addition, in the subgranular zone, BrdU-positive cells colocalized largely, but not exclusively, with eGFP-expressing progenitors (supplemental Fig. $2 d-f$, available at www. jneurosci.org as supplemental material). When quantified, we demonstrate that the number of eGFP-expressing cells that are dividing at the time of sacrifice increases most significantly in the ipsilateral granular layer at 3 and $7 \mathrm{~d}$ after injury (Fig. 4a). Interestingly, on the contralateral side, this occurs as early as $3 \mathrm{~d}$ after injury and is most apparent in the subgranular layers

(Fig. $4 b$ ). We also quantitatively looked at DCX-expressing late progenitors where we observed essentially no DCX-expressing dividing cells in the granular layer at any point after injury although we observed increased numbers in the subgranular layer on both the ipsilateral and contralateral sides $7 \mathrm{~d}$ after injury (Fig. $4 c, d)$. Together, these findings suggest a vulnerability of DCXexpressing type $2 \mathrm{~b}$ neural progenitors and a proliferative response of nestin-expressing type 1 and/or type 2a neural progenitors in the injured environment.

\section{Delta-HSV-TK transgenic mice temporally inhibit neurogenesis}

A major limitation with using BrdU to trace cell fate is that many different types of cells divide, especially after injury. For example, the numbers of microglial cells and astrocytes increase after all forms of brain injury and the notion that these dividing cells may serve as potential sources for neurogenesis remains speculative (Mori et al., 2005; Yokoyama et al., 2006). In addition, early type 1 stem/progenitor cells are known to be relatively slow-dividing, and it is unknown whether they can be induced to proliferate with injury stimuli such as CCI. To determine whether early type 1 neural progenitors are the main source for recovery of the DCXexpressing cells after injury, and to investigate how early neural progenitors repopulate lost dentate gyrus neurons, a modified herpes simplex virus thymidine kinase ( $\delta$-HSV-TK) and eGFPexpressing transgenic mouse line was generated. Ganciclovir is

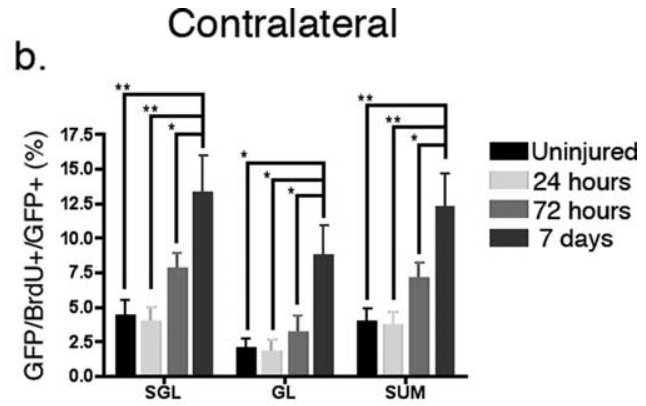

d.

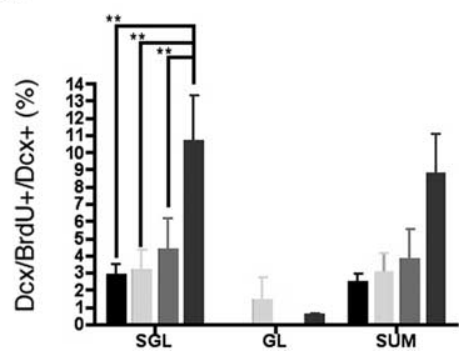

Figure 4. The proliferation index of early and late neural progenitors in the dentate gyrus after injury. $\boldsymbol{a}$, In the ipsilateral

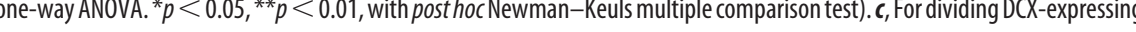
contralateral dentate gyrus, but did not reach statistical significance in the total group ( $p=0.0296,0.4764$, and 0.0553 in the subgranular, granular layers and total, respectively, one-way ANOVA). $N=4$ in each group; error bars indicate SEM.

specifically phosphorylated by HSV-TK and kills dividing cells by acting as a toxic thymidine analog (St Clair et al., 1987). Expression of HSV-TK has been successfully used in the CNS to inducibly ablate GFAP-expressing astrocytes as well as neural stem cells (Morshead et al., 2003; Garcia et al., 2004).

We first generated four transgenic lines using the full-length HSV-TK. Although we were able to demonstrate ganciclovirmediated cellular ablation specifically in neural progenitors, we found that a significant percentage of animals had aberrant brain development and male sterility (data not shown). Previously published data demonstrate that there is a testis-specific enhancer fragment in the HSV-TK gene between the first and second ATG start codons, that renders male mice infertile and may cause other developmental defects (Salomon et al., 1995). Deletion of this enhancer fragment has been demonstrated to recover the fertility defect and reduce toxicity due to its overexpression (Salomon et al., 1995). We therefore generated $\delta$-HSV-TK transgenics after deleting this enhancer element. We used the nestin promoter and its second intron to direct expression of $\delta$-HSV-TK as well as eGFP and restrict their expression to neural progenitors (Fig. 5a). Following pronuclear injection, thirty-one offspring were screened using PCR and three lines were identified that carried the transgene. One of these has subsequently been extensively characterized. Although RT-PCR analysis revealed the expression of $\delta$-HSV-TK in testes and brain in this line (Fig. $5 b$ ), both male and female mice were fertile. Similar to our nestin- 
a.
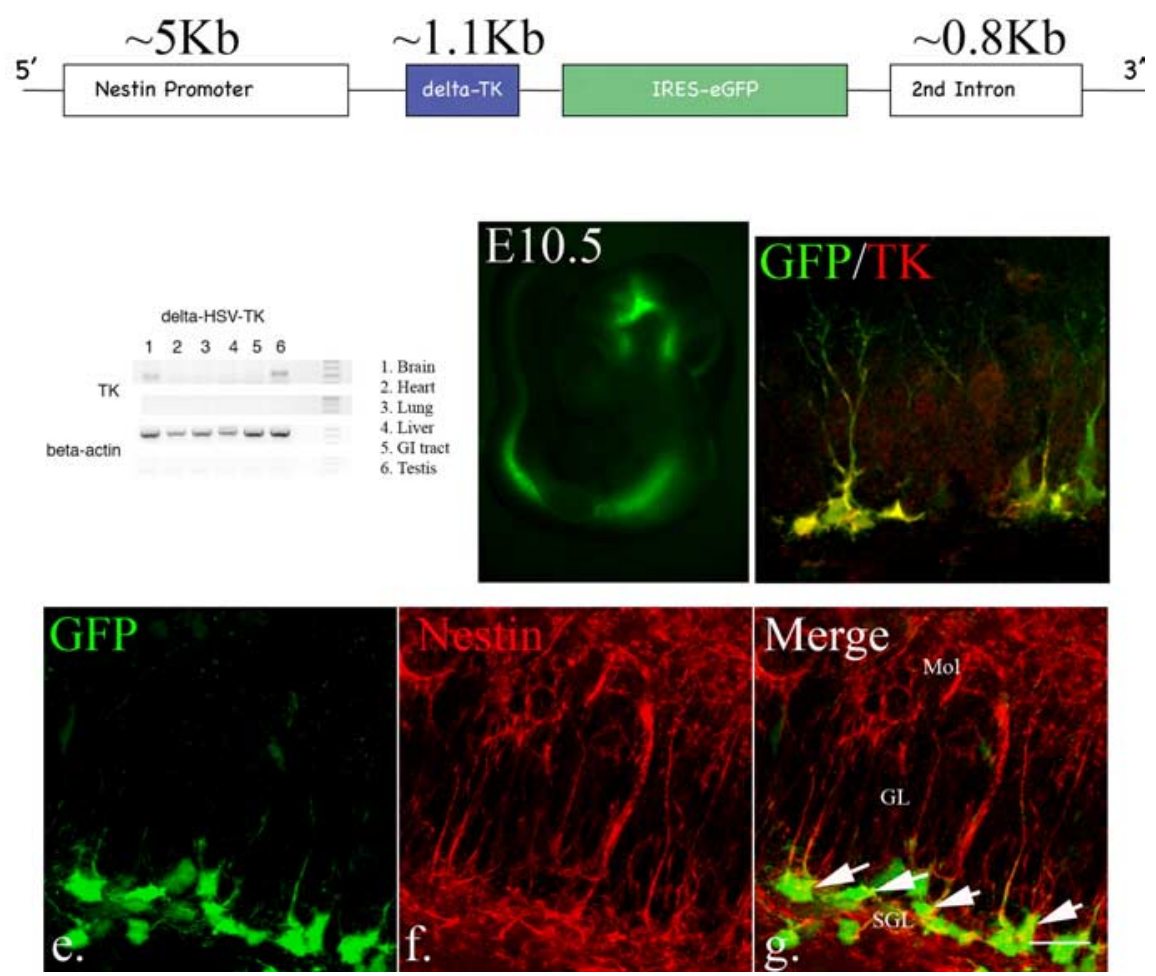

Figure 5. Analysis of the $\delta$-HSV TK transgenic mice. $\boldsymbol{a}$, Construct scheme for modified HSV-TK transgenic mice. $\boldsymbol{b}$, Total RNA was extracted from different tissues from $\delta$-HSV-TK mice. By using primers to verify TK expression, RT-PCR demonstrates that only the testes and brain express the transgene. c, In embryos, endogenous eGFP was visible from E10.5, the earliest examined stage, and expression is restricted to the neural tube. $\boldsymbol{d}$, In adult mice, the expression of eGFP was restricted to neurogenic areas. 0nly eGFP-expressing cells express TK, even after brain injury (d, arrow: type1-like cells; yellow arrow: type2-like cells. $\boldsymbol{e}-\boldsymbol{g}$, Virtually all eGFP-expressing cells in the dentate gyrus also express nestin, including type 1 and type 2 a cells $(98 \% \pm 0.82, n=4$, arrow, scale bar, $20 \mu \mathrm{m})$. Mol, Molecular layer; SGL, subgranular layer; GL, granular layer.

rtTA-M2-IRES-eGFP line, endogenous eGFP expression was visible only in the neural tube during embryonic stages (Fig. $5 c$ ). In the adult brain, eGFP-expressing cells were restricted to known neurogenic areas, namely the subventricular zone and subgranular layer of the dentate gyrus (data not shown). We used antibody staining specific to HSV-TK to confirm its expression in early neural progenitors (Fig. $5 d$ ). In addition, we examined GFP expression with nestin immunostaining to see how much overlap occurred between cells in the subgranular zone that expressed both nestin and GFP (Fig. $5 e-g$ ). By confocal analysis of serial sections through 4 separate mice, we find that there is $98 \% \pm 0.82$ colocalization of GFP-expressing cells within the subgranular layer with nestin-expressing cells. Thus, HSV-TK expression in this transgenic line is coincident with early hippocampal progenitors.

We next examined whether the dynamics of early and late neural progenitors after injury mimic our observations from the nestin-eGFP line described in Figures 1-4. Again, we used 8 -week old $\delta$-HSV-TK mice and performed unilateral CCI injury and analyzed them 3 and $7 \mathrm{~d}$ after injury. As expected, DCXexpressing cells decreased and eGFP-expressing cells were activated in the ipsilateral dentate gyrus $3 \mathrm{~d}$ after injury (Fig. $6 e-h$ ) compared with uninjured controls (Fig. $6 a-d$ ). Seven days after injury, the number of DCX-expressing cells had recovered and eGFP-expressing cells remained active (Fig. $6 i-l$ ). Thus, the dynamics of early and late neural progenitors after injury in nestinHSV-TK transgenic animals phenocopy that observed in a similar line that does not express HSV-TK.

\section{Delta-HSV-TK is functional in vivo}

To examine the functionality of $\delta$-HSV-TK in vivo, 6-week-old male $\delta$-HSV-TK mice were systemically treated with vehicle or ganciclovir $(200 \mathrm{mg} / \mathrm{Kg} / \mathrm{d})$ for 4 weeks via implanted osmotic minipumps. Following a 4 week treatment period, mice were killed and immunostaining was performed to quantify how efficiently early quiescent and slowly dividing (GFP-expressing) and late rapidly dividing (DCX-expressing) were ablated. As demonstrated in Figure $7, a-d$, and using unbiased sterology to quantify absolute numbers, GFP-expressing cells decreased by over $60 \%$ from $33,530 \pm 7636$ in vehicle-treated animals to $9061 \pm 937$ in ganciclovir-treated mice (Fig. 7a,b). Since type 1 GFP-expressing progenitors are largely quiescent, only those dividing during the 4 week exposure to ganciclovir would be affected. To determine the overall efficiency of the system we evaluated type-2 DCX-expressing late progenitors since the 4 week time period is sufficient for all of these cells to have differentiated and those remaining are presumably derived from recently dividing type 1 cells. Here, we find that after 4 weeks of ganciclovir treatment, the DCX-expressing cells were depleted by over $93 \%$ where there were $38,731 \pm 9230$ cells in the vehicletreated animals and $2624 \pm 920$ in the ganciclovir-treated animals (Fig. $7 c, d$ ).

To determine whether other dividing progenitors was affected by ganciclovir treatment in the HSV-TK transgenic, unilateral CCI injury was performed and ganciclovir treatment continued for 7 more days ( 5 weeks total). Three injections of $\mathrm{BrdU}(100 \mathrm{mg} / \mathrm{Kg}$, one injection per day) were given at 3, 4 and 5 d postinjury to label dividing cells. As shown in Figure 7 , the number of GFP-expressing early progenitors remains diminished $(e)$ but there are large numbers of BrdU-expressing cells in the injured area $(f)$. BrdU-positive cells were apparent in other brain regions outside the dentate gyrus (data not shown), while within the dentate gyrus dividing reactive astrocytes and OPCs were not affected based on their incorporation of BrdU (Fig. $7 g-i$ ).

\section{Ablation of neural progenitors inhibits the recovery of DCX- expressing cells after injury}

To examine whether early neural progenitors are required for the recovery of neurogenesis after injury, 6 -week-old male nestin- $\delta$ HSV-TK mice were treated with ganciclovir for 4 weeks to allow for the maturation of existing DCX-expressing cells. Unilateral $\mathrm{CCI}$ injury was then performed and ganciclovir treatment continued for 7 more days to ablate injury-induced eGFP-expressing early neural progenitors. Three injections of BrdU $(100 \mathrm{mg} / \mathrm{Kg}$, one injection per day) were given at 3, 4 and $5 \mathrm{~d}$ postinjury to label dividing cells. A few eGFP-expressing cells incorporated BrdU, which suggests that a small portion of dividing eGFP-expressing cells are either just poised for ablation or might escape it altogether (Fig. 8a,c,d, arrow). However, later developing DCXexpressing cells were not observed in the dentate gyrus $7 \mathrm{~d}$ after 


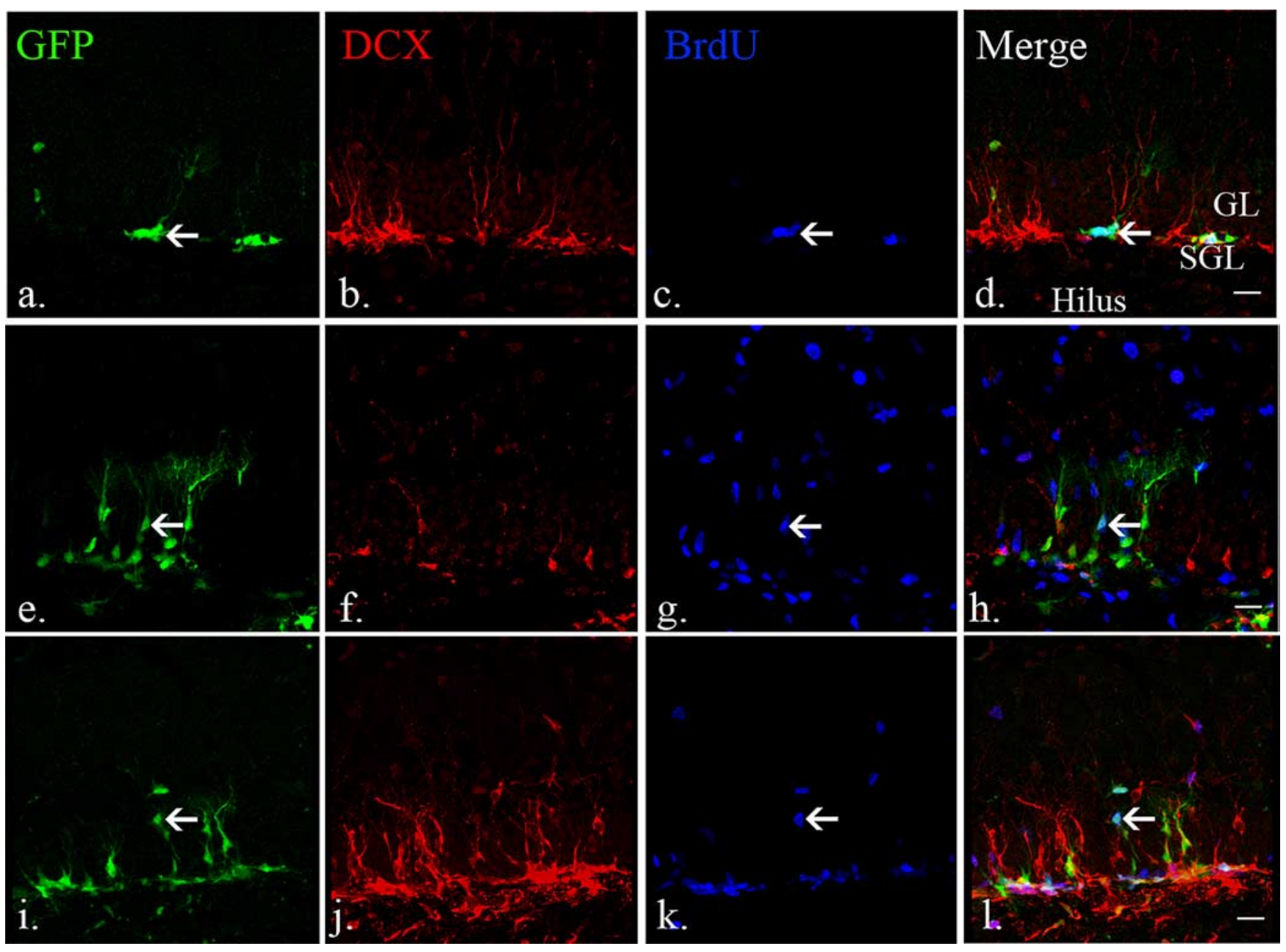

Figure 6. The dynamics of eGFP-expressing early neural progenitors in nestin HSV-TK mice resembles that observed in other nestin-eGFP lines. $\boldsymbol{a}-\boldsymbol{d}$, BrdU/eGFP-positive cells (arrow) were observed in the subgranular layers in the uninjured adult brains whereas DCX-expressing cells were seen in the subgranular and granular layers. $\boldsymbol{e}-\boldsymbol{h}$, Three days after injury, the number of $D C X$-expressing cells is decreased in the ipsilateral dentate gyrus proximal to the injured areas. The number of BrdU/eGFP-positive early neural progenitors increased, especially the ones in the granular layers (arrow). $\boldsymbol{i}-\boldsymbol{I}$, Seven days after injury, lost DCX-expressing cells are replaced and BrdU/eGFP-positive early neural progenitors remained active (arrow). Scale bars, $20 \mu \mathrm{m}$. Mol, Molecular layer; SGL, subgranular layer; GL, granular layer.

injury when treated with ganciclovir (Fig. 8b). These data demonstrate the specificity of ablation in nestin-HSV-TK transgenics following injury and suggests that injury-activated early neural progenitors are required for the recovery of later DCX-expressing cells after injury.

\section{Injury-induced activation of early neural progenitors is} required to repopulate damaged late progenitors

The previous observation suggests that early nestin-expressing progenitors repopulate late DCX-expressing progenitors in both the subgranular and granular layers. To demonstrate this, nestin$\delta$-HSV-TK mice were treated continuously with ganciclovir from 6 to 10 weeks of age. Then, unilateral CCI was performed $1 \mathrm{~d}$ after the removal of ganciclovir. Again, three BrdU injections were given at days 3,4 , and 5 postinjury to determine the cell fate of proliferating cells. Consistent with previous observations, eGFPexpressing early neural progenitors were spread throughout the granular layers. BrdU/DCX-positive cells were seen in both the subgranular and granular layers in the dentate gyrus (Fig. $8 f$ ). These BrdU-positive DCX-expressing cells matured and became NeuN-expressing cells 4 weeks after injury (Fig. 8h). Without injury, repopulation of DCX-expressing cells and their subsequent maturation into $\mathrm{NeuN}$-expressing neurons was seen pri- marily in the subgranular layers (Fig. 8e,g). Consistent with recovery and an increase in DCX-expressing cells after injury, we observed a $100 \%$ increase in NeuN-expressing neurons in the dentate gyrus 4 weeks after injury while compared with ones in uninjured brains (Fig. 8i). We conclude that activation of early neural progenitors is required in injury-induced neurogenesis and those neural progenitors appear to develop into mature dentate gyrus neurons.

\section{Discussion}

TBI is a devastating world health problem and is the leading cause of death in children older than one year of age in the United States (Heegaard and Biros, 2007). Interestingly, most survivors of TBI recover some of their lost neurological function in a process that can take up to two years in children (Ewing-Cobbs et al., 2003). Mechanisms underlying this recovery are completely unknown, and we chose to study whether injury-activated progenitors in mature but still young (8-week-old) mice might participate in recovery. Our data suggest that the activation of early neural progenitors may underlie some of this recovery at least within a relatively immature brain.

Lack of specific neural progenitor markers is a major challenge in studying postnatal neurogenesis, especially in the injured 

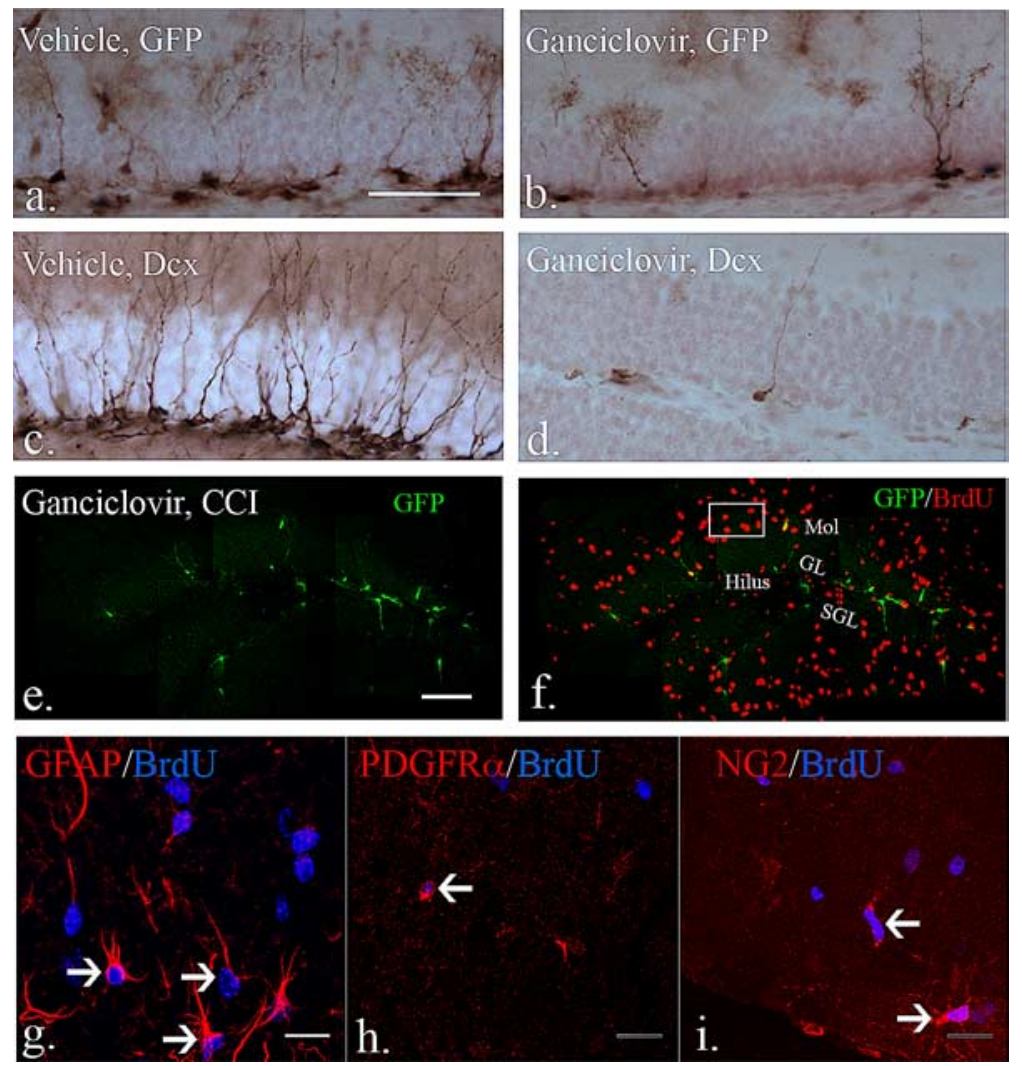

Figure 7. The effects of ganciclovir treatment in eGFP-expressing early neural progenitors. $\boldsymbol{a}, \boldsymbol{b}$, Compared with mice treated with vehicle for 4 weeks, the number of eGFP-expressing cells in the dentate gyrus decreased significantly after 4 week treatment with ganciclovir (vehicle vs ganciclovir: 33,530 \pm 7636 vs $9061 \pm 937$, mean \pm SEM; $p<0.05$ with unpaired Student's $t$ test, $N=3$ each group). $\boldsymbol{c}, \boldsymbol{d}, \mathrm{DCX}$-expressing cells were profoundly depleted (by over $90 \%$ ) in the dentate gyrus after 4 week ganciclovir treatment compared with vehicle-treated animals (vehicle vs ganciclovir: 38,731 \pm 9230 vs $2624 \pm 920 ; p<0.01$ with unpaired Student's $t$ test, $N=3$ each group). $\boldsymbol{e}, \boldsymbol{f}$, After injury and during continuous ganciclovir treatment, there remain diminished numbers of GFP-expressing progenitors $(\boldsymbol{e})$, but large numbers of dividing cells that express BrdU $(\boldsymbol{f})$. ( $\boldsymbol{g}$-i are from representative boxed area from $\boldsymbol{f}$ ). To determine whether ganciclovir treatment affects dividing reactive astrocytes and OPCs after injury, a total of 3 injections of BrdU were given 3, 4 and $5 \mathrm{~d}$ after injury while ganciclovir treatment persisted. $\boldsymbol{g}$, BrdU/GFAPpositive and hypertrophic reactive astrocytes were observed in the molecular layers and hilus in the dentate gyrus (arrows). $\boldsymbol{h}, \boldsymbol{i}$, By using the PDGF $\alpha$ receptor and NG2 as markers for OPCs, BrdU-positive OPCs were observed in the dentate gyrus in the injured brain (arrows). Thus, ganciclovir treatment did not affect dividing reactive astrocytes and $\mathrm{OPCs}$ in the dentate gyrus in the injured brains. Scale bars, (a) $50 \mu \mathrm{m},(\boldsymbol{e}) 100 \mu \mathrm{m}$, and (g) $20 \mu \mathrm{m}$. Mol, Molecular layer; SGL, subgranular layer; GL, granular layer.

brain. For example, nestin, a commonly used marker of early neural progenitors is also expressed in endothelial cells, reactive astrocytes, NG-2-expressing cells and active microglia (Ridet et al., 1997; Belachew et al., 2003; Aguirre and Gallo, 2004; Yokoyama et al., 2006). Other markers, like GFAP, vimentin, RC-2, and Sox-2 are expressed in reactive astrocytes (Ridet et al., 1997). Here, we demonstrate that eGFP-expressing neural progenitors in our transgenic lines specifically label type 1 and type 2a neural progenitors in the dentate gyrus in the hippocampus and are not expressed in other cell types that might express nestin. We further demonstrate that DCX-expressing late neural progenitors are vulnerable to TBI and undergo cell death in the ipsilateral dentate gyrus, a result consistent with recent studies in both traumatic and hypoxic brain injury (Gao et al., 2008; Miles and Kernie, 2008). The number of DCX-expressing late neural progenitors reemerges $7 \mathrm{~d}$ after injury and we further show that DCX-expressing late neural progenitors are derived from eGFPexpressing early neural progenitors. We also demonstrate that the development of newly born neurons in the traumatically injured brain occurs not only in the subgranular layer of the dentate gyrus but in the granular layer as well.
The subgranular layer of the dentate gyrus is one of two primary areas where adult neural progenitors reside (Eriksson et al., 1998). In this study, we find that, although the majority of early neural progenitors are in the subgranular layers, a small population of early neural progenitors is also apparent in the granular layer. These cells have been examined in other nestin-eGFP-expressing transgenic lines, although not described in detail (Yamaguchi et al., 2000; Mignone et al., 2004). We demonstrate that such cells are type 1-like early neural progenitors, and are relatively quiescent compared with ones in the subgranular layers. Interestingly, they become active in the injured brain and apparently give rise to neurons in the dentate gyrus. Recent data demonstrate that a small population of neural progenitors in the retina is able to undergo final mitosis and develop into neurons locally (Godinho et al., 2007). This suggests that a similar mechanism may exist in the more mature dentate gyrus. It remains unclear whether it is the subgranular type 1 early progenitors or the granular type 1-like progenitors that contribute most to injury-induced neurogenesis within the dentate gyrus.

Several methods have been used to inhibit neurogenesis, including applying chemical inhibitors of mitosis or brain irradiation (Shors et al., 2001; Gourevitch et al., 2004; Rola et al., 2004; Winocur et al., 2006). In these studies, lack of specificity and damage caused by the inhibitor itself are major limitations for using such techniques in the context of TBI (Leuner et al., 2006; Wojtowicz, 2006). To overcome these limitations, a transgenic line that has a modified $\delta$-HSV-TK driven by the nestin promoter and its second intron regulatory element was generated to allow for temporally regulated ablation of dividing neural progenitors by administration of ganciclovir. A similar strategy has been reported using full-length HSV-TK driven by the human GFAP promoter (Bush et al., 1998, 1999; Morshead et al., 2003; Garcia et al., 2004; Myer et al., 2006; Saxe et al., 2006, 2007). Several critical issues render this line suboptimal for studying neurogenesis, particularly in the setting of brain injury. The males are infertile due to overexpression of HSV-TK in the testes and maintenance of this line is difficult secondary to intestinal ischemia associated with larger doses of ganciclovir (Salomon et al., 1995). Another limitation is due to the use of the human GFAP promoter, which directs expression of HSV-TK in neural progenitors as well as in mature astrocytes (Bush et al., 1999; Morshead et al., 2003; Garcia et al., 2004). Therefore, ablation is not restricted to neural progenitors, but also occurs in reactive astrocytes in the injured brain. In addition, administering ganciclovir to human GFAP-HSV-TK transgenics causes systemic illness and intra-cerebroventricular administration of ganciclovir introduces an acquired injury not unlike TBI (Bush et al., 1998). It is unclear whether behavioral phenotypes from more recent studies on the human GFAP-HSV-TK transgenic mice 

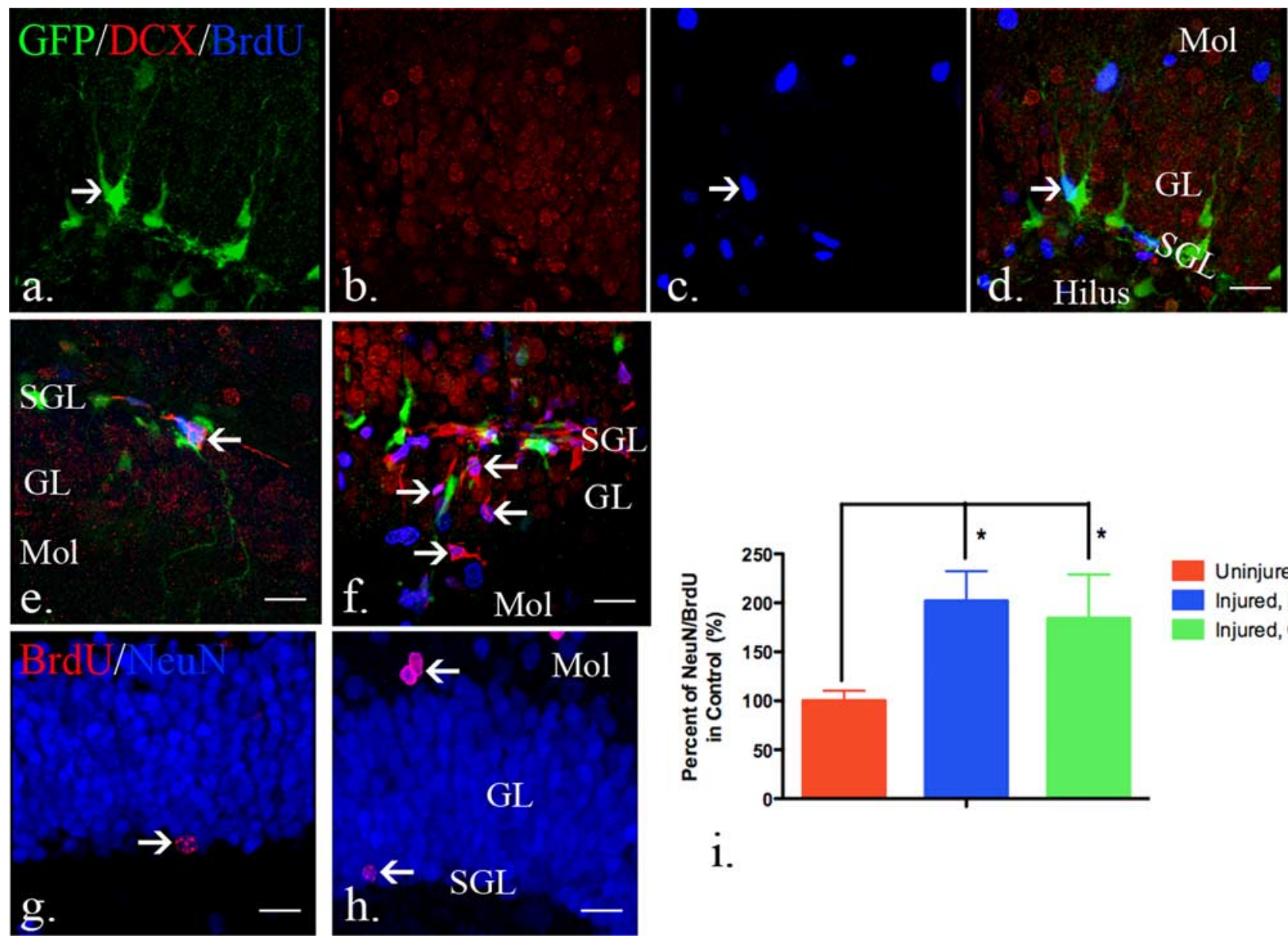

Uninjured

Injured, Ipsi

Injured, Contra

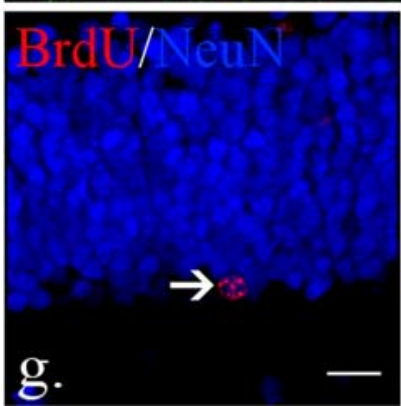

1.

Figure 8. Quiescent type I progenitors are activated after injury. $\boldsymbol{a}-\boldsymbol{d}$, Ten-week-old nestin-HSV-TK transgenic mice were given ganciclovir continuously starting at 6 weeks of age. No DCX-expressing cells were observed in the subgranular zone although eGFP-expressing cells were still observed in the subgranular layers and BrdU-positive cells were detected in the molecular layer and hilus. Only occasional BrdU + cells expressed GFP (arrow, $\boldsymbol{c}) \cdot \boldsymbol{e}, \boldsymbol{f}$, To demonstrate whether the remaining eGFP-expressing cells regenerate neural progenitor populations in the injured brain after the removal of ganciclovir, 6-week-old mice were treated with ganciclovir for 4 weeks to allow for the maturation of the existing DCX-expressing cells. A total 3 injections of BrdU were given 3,4 and $5 \mathrm{~d}$ after removal of ganciclovir treatment. Seven days or 4 weeks after removal, mice were killed for examination of regeneration of DCX-expressing late neural progenitors or NeuNexpressing neurons. $\boldsymbol{e}$, Seven days after the removal of ganciclovir, BrdU/DCX-positive cells were observed in the subgranular layers in the uninjured brains (arrow, $\boldsymbol{e}$ ). $\boldsymbol{f}$, In the injured brain, BrdU/DCX-positive cells are observed in the granular layers as well as subgranular layers (arrows, $\boldsymbol{f}$ ). $\boldsymbol{g}$, Four weeks after ganciclovir removal, mature BrdU/NeuN-positive cells were found in the subgranular layers in the uninjured brains (arrow, $\boldsymbol{g})$. $\boldsymbol{h}$, Similar to the distribution of BrdU/DCX-positive cells in the dentate gyrus in the injured brain, BrdU/NeuN-positive mature neurons were observed in the subgranular and granular layers (arrows, $\boldsymbol{h}) 4$ weeks after $\mathrm{CCl}$ injury. $\boldsymbol{i}$, More BrdU-expressing neurons were quantified in the dentate gyrus in both hemispheres after injury when compared with ones in the uninjured brains. (control: $751 \pm 220$, ipsilateral: $1518 \pm 457$, and contralateral: $1383 \pm 676$, data presented as mean \pm SD; $p=0.0183$ with one-way ANOVA. ${ }^{*} p<$ 0.05 , with Newman-Keuls multiple comparison test). $N=4$ in each group and error bars indicate SEM. Scale bars, $20 \mu \mathrm{m}$. Mol, Molecular layer; SGL, subgranular layer; GL, granular layer.

were due to ablation of neural progenitors specifically (Saxe et al., 2006, 2007). To obviate some of these concerns, we removed the fragment between the first and second start codon from fulllength HSV-TK (Salomon et al., 1995; Cohen et al., 1998) and used a portion of the nestin promoter known to be specific for early progenitors. As expected, heterozygous males are fertile and there is no apparent abnormality in the transgenic mice, even after 6 weeks of systemic administration of ganciclovir.

The development of late-born neurons involves several stages, from early neural progenitors, committed late neuronal precursors, immature migrating neurons, to mature neurons (Ming and Song, 2005). Within these stages, type 1 , type $2 \mathrm{a}$, and type $2 \mathrm{~b}$ cells are able to proliferate (Kronenberg et al., 2003), although the timeline in which this occurs remains unclear (Seri et al., 2004; Zhao et al., 2006). By using the nestin- $\delta$-HSV-TK transgenic mice in this study, a four-week treatment with ganciclovir allowed for existing DCX-expressing late progenitors to develop to the next stage, whereas nondividing type 1-like early neural progenitors remained in the dentate gyrus. This suggests that transgene-expressing cells represent most, if not all, of the early neural progenitors since otherwise a certain percentage of DCXexpressing cells would be detected no matter how long ganciclovir treatment occurs. In this study, type $2 \mathrm{~b}$-like cells were seen $7 \mathrm{~d}$ after the removal of ganciclovir and NeuN-expressing cells were observed 4 weeks after its removal. Although this observation is consistent with existing data, more detailed experiments are required to determine the precise timing of the development of newly born neurons from type 1 neural progenitors (Zhao et al., 2006).

Many studies demonstrate that a variety of different kinds of brain injuries stimulate hippocampal neurogenesis (Kernie et al., 2001; Chirumamilla et al., 2002; Darsalia et al., 2005; Parent et al., 2006; Rola et al., 2006; Richardson et al., 2007; Urrea et al., 2007; Miles and Kernie, 2008). Here, we further demonstrate that, by ablating injury-activated early neural progenitors, we can inhibit injury-induced neurogenesis. Although reactive astrocytes, NG2-expressing cells, and activated microglia have been reported as potential sources for neurogenesis (Ridet et al., 1997; Belachew et 
al., 2003; Aguirre and Gallo, 2004; Yokoyama et al., 2006), this study excludes these possibilities, at least in the hippocampus. Seven days after the removal of ganciclovir, more type 2b-like DCX-expressing cells were observed in the subgranular and granular layers in injured brains compared with uninjured controls. Our data demonstrate that it takes 4 weeks for newly born NeuNexpressing neurons to become visible in the injured brain after the removal of ganciclovir. This therefore suggests that injury enhances neurogenesis by stimulating proliferation of neural progenitors, but that it does not accelerate neuronal maturation.

Recent work also suggests that the cognitive recovery that occurs following TBI is associated with integration of newly generated dentate granule neurons (Sun et al., 2007). The data presented here demonstrate that in order for this to occur, early type 1 progenitors need to become activated by injury to repopulate lost later progenitors. The signals responsible for this activation are unknown, and it remains unclear whether this is a local phenomenon exclusive to the injured environment that consists of reactive astrocytes, activated microglia, as well as infiltrating mononuclear cells. Since activation of type-1 progenitors occurs not only on the ipsilateral side of injury but also on the contralateral side, it appears that circulating factors may direct this stimulation. Since it is known that type 1 cells are closely aligned with the dentate gyrus vasculature and that endothelial-derived factors stimulate neurogenesis, it may be that changes in this niche mediate at least some of these observations (Palmer et al., 2000; Shen et al., 2004). Future studies will determine the molecular cues involved in what appears to be a required pathway for recovery following TBI.

\section{References}

Aguirre A, Gallo V (2004) Postnatal neurogenesis and gliogenesis in the olfactory bulb from NG2-expressing progenitors of the subventricular zone. J Neurosci 24:10530-10541.

Belachew S, Chittajallu R, Aguirre AA, Yuan X, Kirby M, Anderson S, Gallo V (2003) Postnatal NG2 proteoglycan-expressing progenitor cells are intrinsically multipotent and generate functional neurons. J Cell Biol 161:169-186.

Bramlett HM, Green EJ, Dietrich WD (1997) Hippocampally dependent and independent chronic spatial navigational deficits following parasagittal fluid percussion brain injury in the rat. Brain Res 762:195-202.

Bush TG, Savidge TC, Freeman TC, Cox HJ, Campbell EA, Mucke L, Johnson MH, Sofroniew MV (1998) Fulminant jejuno-ileitis following ablation of enteric glia in adult transgenic mice. Cell 93:189-201.

Bush TG, Puvanachandra N, Horner CH, Polito A, Ostenfeld T, Svendsen CN, Mucke L, Johnson MH, Sofroniew MV (1999) Leukocyte infiltration, neuronal degeneration, and neurite outgrowth after ablation of scarforming, reactive astrocytes in adult transgenic mice. Neuron 23:297-308.

Chirumamilla S, Sun D, Bullock MR, Colello RJ (2002) Traumatic brain injury induced cell proliferation in the adult mammalian central nervous system. J Neurotrauma 19:693-703.

Cohen JL, Boyer O, Salomon B, Onclerco R, Depetris D, Lejeune L, DubusBonnet V, Bruel S, Charlotte F, Mattéi MG, Klatzmann D (1998) Fertile homozygous transgenic mice expressing a functional truncated herpes simplex thymidine kinase delta TK gene. Transgenic Res 7:321-330.

Darsalia V, Heldmann U, Lindvall O, Kokaia Z (2005) Stroke-induced neurogenesis in aged brain. Stroke 36:1790-1795.

Eriksson PS, Perfilieva E, Björk-Eriksson T, Alborn AM, Nordborg C, Peterson DA, Gage FH (1998) Neurogenesis in the adult human hippocampus. Nat Med 4:1313-1317.

Ewing-Cobbs L, Barnes MA, Fletcher JM (2003) Early brain injury in children: development and reorganization of cognitive function. Dev Neuropsychol 24:669-704.

Fukuda S, Kato F, Tozuka Y, Yamaguchi M, Miyamoto Y, Hisatsune T (2003) Two distinct subpopulations of nestin-positive cells in adult mouse dentate gyrus. J Neurosci 23:9357-9366.

Garcia AD, Doan NB, Imura T, Bush TG, Sofroniew MV (2004) GFAP- expressing progenitors are the principal source of constitutive neurogenesis in adult mouse forebrain. Nat Neurosci 7:1233-1241.

Gao X, Deng-Bryant Y, Cho W, Carrico KM, Hall ED, Chen J (2008) Selective death of newborn neurons in hippocampal dentate gyrus following moderate experimental traumatic brain injuy. J Neurosci Res 86:2258-2270.

Godinho L, Williams PR, Claassen Y, Provost E, Leach SD, Kamermans M, Wong RO (2007) Nonapical symmetric divisions underlie horizontal cell layer formation in the developing retina in vivo. Neuron 56:597-603.

Gourevitch R, Rocher C, Le Pen G, Krebs MO, Jay TM (2004) Working memory deficits in adult rats after prenatal disruption of neurogenesis. Behav Pharmacol 15:287-292.

Guillery RW (2002) On counting and counting errors. J Comp Neurol 447:1-7.

Heegaard W, Biros M (2007) Traumatic brain injury. Emerg Med Clin North Am 25:655-678, viii.

Kempermann G, Gast D, Kronenberg G, Yamaguchi M, Gage FH (2003) Early determination and long-term persistence of adult-generated new neurons in the hippocampus of mice. Development 130:391-399.

Kernie SG, Erwin TM, Parada LF (2001) Brain remodeling due to neuronal and astrocytic proliferation after controlled cortical injury in mice. J Neurosci Res 66:317-326.

Kronenberg G, Reuter K, Steiner B, Brandt MD, Jessberger S, Yamaguchi M, Kempermann G (2003) Subpopulations of proliferating cells of the adult hippocampus respond differently to physiologic neurogenic stimuli. J Comp Neurol 467:455-463.

Leuner B, Gould E, Shors TJ (2006) Is there a link between adult neurogenesis and learning? Hippocampus 16:216-224.

Levin HS (1998) Cognitive function outcomes after traumatic brain injury. Curr Opin Neurol 11:643-646.

Mandyam CD, Norris RD, Eisch AJ (2004) Chronic morphine induces premature mitosis of proliferating cells in the adult mouse subgranular zone. J Neurosci Res 76:783-794.

Marshall LF (2000) Head injury: recent past, present, and future. Neurosurgery 47:546-561.

Mignone JL, Kukekov V, Chiang AS, Steindler D, Enikolopov G (2004) Neural stem and progenitor cells in nestin-GFP transgenic mice. J Comp Neurol 469:311-324.

Miles DK, Kernie SG (2008) Hypoxic-ischemic brain injury activates early hippocampal stem/progenitor cells to replace vulnerable neuroblasts. Hippocampus 18:793-806.

Ming GL, Song H (2005) Adult neurogenesis in the mammalian central nervous system. Annu Rev Neurosci 28:223-250.

Mori T, Buffo A, Götz M (2005) The novel roles of glial cells revisited: the contribution of radial glia and astrocytes to neurogenesis. Curr Top Dev Biol 69:67-99.

Morshead CM, Garcia AD, Sofroniew MV, van Der Kooy D (2003) The ablation of glial fibrillary acidic protein-positive cells from the adult central nervous system results in the loss of forebrain neural stem cells but not retinal stem cells. Eur J Neurosci 18:76-84.

Myer DJ, Gurkoff GG, Lee SM, Hovda DA, Sofroniew MV (2006) Essential protective roles of reactive astrocytes in traumatic brain injury. Brain 129:2761-2772.

Palmer TD, Willhoite AR, Gage FH (2000) Vascular niche for adult hippocampal neurogenesis. J Comp Neurol 425:479-494.

Parent JM, Elliott RC, Pleasure SJ, Barbaro NM, Lowenstein DH (2006) Aberrant seizure-induced neurogenesis in experimental temporal lobe epilepsy. Ann Neurol 59:81-91.

Richardson RM, Sun D, Bullock MR (2007) Neurogenesis after traumatic brain injury. Neurosurg Clin N Am 18:169-181, xi.

Ridet JL, Malhotra SK, Privat A, Gage FH (1997) Reactive astrocytes: cellular and molecular cues to biological function. Trends Neurosci 20:570-577.

Rola R, Raber J, Rizk A, Otsuka S, VandenBerg SR, Morhardt DR, Fike JR (2004) Radiation-induced impairment of hippocampal neurogenesis is associated with cognitive deficits in young mice. Exp Neurol 188:316-330.

Rola R, Mizumatsu S, Otsuka S, Morhardt DR, Noble-Haeusslein LJ, Fishman K, Potts MB, Fike JR (2006) Alterations in hippocampal neurogenesis following traumatic brain injury in mice. Exp Neurol 202:189-199.

Salomon B, Maury S, Loubière L, Caruso M, Onclercq R, Klatzmann D (1995) A truncated herpes simplex virus thymidine kinase phosphory- 
lates thymidine and nucleoside analogs and does not cause sterility in transgenic mice. Mol Cell Biol 15:5322-5328.

Saxe MD, Battaglia F, Wang JW, Malleret G, David DJ, Monckton JE, Garcia AD, Sofroniew MV, Kandel ER, Santarelli L, Hen R, Drew MR (2006) Ablation of hippocampal neurogenesis impairs contextual fear conditioning and synaptic plasticity in the dentate gyrus. Proc Natl Acad Sci U S A 103:17501-17506.

Saxe MD, Malleret G, Vronskaya S, Mendez I, Garcia AD, Sofroniew MV, Kandel ER, Hen R (2007) Paradoxical influence of hippocampal neurogenesis on working memory. Proc Natl Acad Sci U S A 104:4642-4646.

Seri B, García-Verdugo JM, Collado-Morente L, McEwen BS, Alvarez-Buylla A (2004) Cell types, lineage, and architecture of the germinal zone in the adult dentate gyrus. J Comp Neurol 478:359-378.

Shen Q, Goderie SK, Jin L, Karanth N, Sun Y, Abramova N, Vincent P, Pumiglia K, Temple S (2004) Endothelial cells stimulate self-renewal and expand neurogenesis of neural stem cells. Science 304:1338-1340.

Shi J, Miles DK, Orr BA, Massa SM, Kernie SG (2007) Injury-induced neurogenesis in Bax-deficient mice: evidence for regulation by voltage-gated potassium channels. Eur J Neurosci 25:3499-3512.

Shors TJ, Miesegaes G, Beylin A, Zhao M, Rydel T, Gould E (2001) Neurogenesis in the adult is involved in the formation of trace memories. Nature 410:372-376.

St Clair MH, Lambe CU, Furman PA (1987) Inhibition by ganciclovir of cell growth and DNA synthesis of cells biochemically transformed with herpesvirus genetic information. Antimicrob Agents Chemother 31:844-849.

Sun D, McGinn MJ, Zhou Z, Harvey HB, Bullock MR, Colello RJ (2007)
Anatomical integration of newly generated dentate granule neurons following traumatic brain injury in adult rats and its association to cognitive recovery. Exp Neurol 204:264-272.

Urrea C, Castellanos DA, Sagen J, Tsoulfas P, Bramlett HM, Dietrich WD (2007) Widespread cellular proliferation and focal neurogenesis after traumatic brain injury in the rat. Restor Neurol Neurosci 25:65-76.

Winocur G, Wojtowicz JM, Sekeres M, Snyder JS, Wang S (2006) Inhibition of neurogenesis interferes with hippocampus-dependent memory function. Hippocampus 16:296-304.

Wojtowicz JM (2006) Irradiation as an experimental tool in studies of adult neurogenesis. Hippocampus 16:261-266.

Yamaguchi M, Saito H, Suzuki M, Mori K (2000) Visualization of neurogenesis in the central nervous system using nestin promoter-GFP transgenic mice. Neuroreport 11:1991-1996.

Yokoyama A, Sakamoto A, Kameda K, Imai Y, Tanaka J (2006) NG2 proteoglycan-expressing microglia as multipotent neural progenitors in normal and pathologic brains. Glia 53:754-768.

Yu TS, Dandekar M, Monteggia LM, Parada LF, Kernie SG (2005) Temporally regulated expression of Cre recombinase in neural stem cells. Genesis 41:147-153.

Zhao C, Teng EM, Summers RG Jr, Ming GL, Gage FH (2006) Distinct morphological stages of dentate granule neuron maturation in the adult mouse hippocampus. J Neurosci 26:3-11.

Zimmerman L, Parr B, Lendahl U, Cunningham M, McKay R, Gavin B, Mann J, Vassileva G, McMahon A (1994) Independent regulatory elements in the nestin gene direct transgene expression to neural stem cells or muscle precursors. Neuron 12:11-24. 